\title{
Factors That Affect the Morale of Employees in the Institution of Higher Learning in South Africa
}

\author{
Njabulo Khumalo ${ }^{1}$ \\ ${ }^{1}$ Faculty of Management Sciences, Durban University of Technology, South Africa \\ Correspondence: Njabulo Khumalo, Faculty of Management Sciences, Durban University of Technology, South \\ Africa. https://orcid.org/0000-0002-7480-6715
}

Received: September 18, 2021

Accepted: November 18, 2021

Online Published: November 23, 2021

doi:10.5430/ijhe.v11n3p58

URL: https://doi.org/10.5430/ijhe.v11n3p58

\begin{abstract}
The paper focuses on assessing and identifying the factors that affect the morale of employees in the institution of higher learning in South Africa. Employee morale is a drive to keep the organisation growing and achieve its objectives. In the worldwide ranking there are two institutions of higher learning that are featured in the top 250 of the universities which could be the result that employees are engaged in their institutions. However, it is imperative to maintain or improve more by understanding and dealing with the factors that may contribute negatively in the institutions of higher learning in SA. A quantitative approach was utilised for the paper and a questionnaire was constructed to collect data from 108 academics and support staff. A stratified approach method wad used and divide participant into groups academics and support employees. All data collected was analysed using SPSS version 22 and the findings of the paper reveals that the level of employee morale was very low and further reveals that management support and feedback, conditions of work, remuneration packages, benefits, promotion processes and recognition, communication and understanding of policies as well as treatment and workload were the crucial factors affect the morale of employees. The paper recommends that all institutions of higher learning to review their own policies and ensure that all stakeholders of their institutions understand them effectively. Similar research should be conducted in other institutions of higher learning as well in order to generalise or enrich the findings of the present paper which serve as a wake-up call.
\end{abstract}

Keywords: employee, morale, institution of higher learning, performance, academics

\section{Introduction}

There is a process of transformation going in the institutions of higher learning in South Africa (SA). Sixty five percent $(65 \%)$ of institutions of higher learning in SA in the two decades have been confronted with a problem of low employee morale. Senior managers and leaders of these institutions of higher learning are seeking strategies and utilising best resources to get the talent employees available from the market. The challenges commence in maintening the talented employees while managers and leaders often does not always know how to bring out the best in them in terms of growth and development. Employees get discouraged to be under-utilised and being in the environment with no growth. This happens when an employee has to occupy one position for more than twenty years without development. Unchallenging environments with little or no opportunity for professional growth and advancement are the challenge often contribute to low employee morale (Ngambi, 2011). Authors who researched under the topics nationally (Zweni, 2004; Ngambi, 2011) confirmed that the negative experiences of employees were created by dissatisfaction caused by a number of factors in the workplace, often lead to low staff morale. Low employee morale has resulted to negative performance and impact on employee's health related conditions such as stress, depression and burnout. While in the institutions of higher learning the positive work climate increases academic performance and enhances social and emotional competencies. To date, little research has been conducted on the assessment of employee morale in Africa especially in the institutions of higher learning in SA, there is a serious need to close a gap by informing the institutions of higher learning to know and plan in advance on how to deal with the factors that can been associated with low morale as they impact negatively on employees in the institutions of higher learning in SA.

\section{Literature Review}

2.1 Employee Morale

Employee morale is defined as a combination of feelings, attitudes and emotions of employees which resulted to the 
behaviour of work and influence the achievement of the organisational goals (Bound, Evans, \& Karmel, 2018). Ogbe, Olubmmi and Okorode (2019) reveals that when an employee displays a negative attitude about the organisation that will influence others and affect the performance. Webb (2014) reveals that for academics' curriculum issues, workload rapport among academics and heads are the challenges with lead to morale. Erasmus (2020) indicate that if communication of training opportunities, promotion chances and departmental goals are not clear stated to employees it could be the reasons of lack in managerial skills. Therefore, management should understand that morale of employees would suffer and talent will be dissatisfied will end up on resigning and look of employment outside.

\subsection{Institutional Culture}

The culture of the organization has an impact of on employee's morale which includes the rule, beliefs, values and behavior exist and how things are conducted (Bowles and Copper, 2009). Boomer (2008) defined the organisational culture as the denial of low trust resulted in deprived show. Organisational culture is the pattern of assumptions that given to a group to cope challenges of external adaptation and inside integration. O'Maolalaidh (2000) said a culture infrastructure is known as who is who in the workplace and how they want to is been seen by employees. All departments make it clear who they are and what they do in the organisation. Bowles and Cooper (2009) developed a morale model based on culture as follows:

a) Step 1- Leadership determines overall "culture and values for the organisation based on life experience, beliefs, values, and needs of the organisation."

b) Step 2- Culture initiates "how things are done", including Human Resource policies and practices, selections for positions; management styles and how employees are treated.

c) Step 3-Employees are affected by Human Resource policies, procedures, management styles and many other aspects of the overall culture, as part of daily work life. The combined net result of their reactions is their individual morale, which is also influenced by and merges with the morale of the group to form the group morale.

d) Step 4- In some organisations morale is measured and analysed. Results are communicated to everyone from senior management to non- management employees. Adjustment to HR practices and procedures are made along with changes in personnel who are identified as being a source of lower morale.

According to Drew (2011) culture in the organization contribute more on employee morale and productivity thorough leadership that does not serve as exemplars. Stevens (2009) in Ngambi (2011) confirms that there is a relationship between culture and management on low employee morale in the organisation. Labour turnover increases due to employees who leave the culture and mismanagement.

\subsection{Causes of Low Staff Morale}

While Kinjerski and Skrypnek (2006) indicate that the current trends near organisational economisation have a negative effect on employee morale. Further indicates that uncommitted employees are the consequences of low staff morale. These contributes to poor employee morale which spills over to activities in the organisation and productivity suffers (Makawatsakul \& Kleiner, 2003). Organisations need to understand that mistake is a learning curve, employees need to make mistakes and be corrected in a good way. There is a high level of risk associated with organisations where there are no preparation talented and experience people. One goals of the organisations is to create clients, therefore attention must be paid to the most valuable asset. Everything that occurs to employees in the workplace, either positively or negatively has a little impact on productivity (Bowles \& Copper, 2009). An organisation that is led by inexperienced or poor management creates low employee morale are also causes by managers who do not lead by example. Conflict based on employees, teams and departments contribute to employee morale negative. Once employees feel unappreciated in the workplace, level of working hard reduces (Haddock, 2010).

External recruitment contributes to employee morale to internally employee and end up losing opportunities for progression. Poor communication is one of the key elements that contributes to employee morale (Haddock, 2010). When employees feel that their positions are at risk of redundancy; their morale and if rumors become rife in the workplace, productivity decreases (Haddock, 2010). Bowles and Coppers (2009) highlighted factors that affect employee morale in the workplace and these include: Individual job and organisation image Employees deliberate the work and perception of the customers towards the organisation. It basically looks at what internal staff said about the organisation to their friends and family. Compensation and benefit If employees are not fairly compensated, the employees look for other jobs externally (Fathaniy, 2011). Career and development Employees have chance for progression and advancement. Hiring employees externally rather than developing those in the system internal causes low morale to those who are ignored. Fathaniy (2011) said employees need to be given opportunities to advance 
careers in order to grow and develop skills. Production Employees do not comply because of unclear directions made by poor management behaviour. Productivity suffers at the end of the day. Working conditions Physical working conditions such as tools, equipment and working space are not provided to some employees (Bowles \& Coppers, 2009).

According to Makawatsakul and Kleiner (2003) downsizing is a way to increase profit in the organisation and affect employees through dismissal based on operational requirements. Downsizing brings problems in the workplace rather than to solve and satisfy financial objectives. Employees' uncertainty and fear paralyses operations and lead to decline in trust and motivation. Organisations downsize to eliminate expenditures by encouraging staff efficiency to maintain profit level. Work reduction changes the attitude, value and culture of the organisation. Downsizing employs tactics like early retirement, transfer and out-placement, buy-out packages, job banks and layoffs or firing. Attrition is normal reduction of leaving the organisation for reasons such as death, early retirement or resignation. Makawutsakul and Kleiner (2003) said survivor sicknesses are words that also refer to staff morale challenges among employees remaining in the workplace after retrenchment. Employees fear insecurity and uncertainty. When employees are frustrated normally viewed with sadness and anger. Without the intervention of management on employee wellbeing, organisations are experiencing long service employees who leave the employment due to poor management and easily replaced by those will be bored and also leave (Drew, 2011). Adams and Bond (2000) emphasizes that employee turnover is influenced by job dissatisfaction and workplace stress.

Commitment of employees is disappearing when there are not treated with required respect. High morae of employees achieved through management understands the commitment in the organization O'Maolalaidh, (2000). In SA the teacher's career is one that demonstrate high low morale because of remuneration (Fard et al., 2010). Lemerle (2005) identifies sleep disturbance and heart diseases as a psychopathological symptom of low morale on employee. Overloaded with work develops confusion and employees fails to meet the targets required (Redfern, Hannan, Norman and Martin (2002). One of the institutions of higher learning in SA was rated at 35\% low salaries and unfair labour practices compare to other tertiary institutions. Senior academics and professors were earning less than junior employees (Africa, Mosia and Zakuza, 2011). Organiations to should consider that rewards must be aligned with knowledge and competencies at a market value (Fathaniy, 2011). Benefits does not improve performance however, influence the satisfaction of employees' commitment (O'Moalalaidh, (2000). Promotion policies should be revised in a way that promote quality and contribution of employees (Bourini, 2010). Management in the institutions of higher learning need to intervene quickly before other institutions take their talent employees (Makawatsakul and Kleiner (2003). Therefore, is it imperative to for organization to understand and deal with factors that affect the morale of employees.

\section{Methods}

\subsection{Research Design}

According to Nayak and Singh (2021) research is a search of knowledge or a scientific and systematic search for information. Therefore, this paper searches for information related to factors that affect the morale of employees in the institutions of higher learning. The descriptive design was utilised because it provides the situation and used to collect data from the participants and recommend (Creswell, 2006). Therefore, the quantitative approach was utilised for this paper.

\subsection{Research Participants}

The research participants of the paper were 108 employees of the institution of higher learning in SA. A stratified approach method was used and divide participants into groups of academics and support employees.

\subsection{Instrument and Data Collection}

The instrument used in this paper and administered to participants was a questionnaire with five Likert-Scales constructed in English and isiZulu. First section required a demographics information of the participants and sections followed were questions aligned with the aim of the paper and requires answers like 1-very dissatisfied, 2- dissatisfied, 3-netural, satisfied, and 5 - very satisfied. The instrument was pre-tested to develop the feasibility of techniques used to determine the reliability for a final sample of the paper.

\subsection{Data Analysis Techniques}

Data was analysed using SPSS version 22 and generated data into tables. The descriptive statistic, median test, chi-square test, P-values and binomial tests were used for the paper. 


\subsection{Ethics Approval and Consent to Participate}

The author adheres to the University Ethics Policy while conducting research. The researcher asked for permission to do a study and permission was granted.

\section{Results}

108 questionnaires returned from participants namely, academic and support employees and the findings were as follows:

Table 1. Gender

\begin{tabular}{ll}
\hline Gender & $\mathbf{1 0 0 \%}$ \\
\hline Female & $47.2 \%$ \\
Male & $50.9 \%$ \\
Did not declare & $1.9 \%$
\end{tabular}

As shown in Table 1, above indicate that the majority of the participants were males with $50.9 \%$ who participated in the paper.

Table 2. Race

\begin{tabular}{ll}
\hline Race & $\mathbf{1 0 0 \%}$ \\
\hline Black & $89.8 \%$ \\
White & $2.8 \%$ \\
Indian & $2.8 \%$ \\
Coloured & $2.8 \%$ \\
Did not declare & $1.9 \%$
\end{tabular}

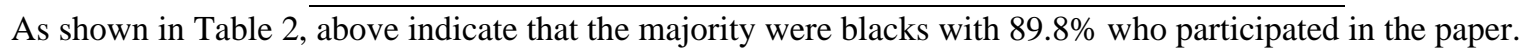

Table 3. Highest Qualification

\begin{tabular}{lc}
\hline Highest Qualification & $\mathbf{1 0 0 \%}$ \\
\hline National Certificate & $20.4 \%$ \\
National Diploma & $14.8 \%$ \\
B. Tech/ B. Degree/ Honours Degree & $28.9 \%$ \\
M. Tech/ Master's Degree & $1.9 . \%$ \\
D. Tech/ PhD & $24.1 \%$ \\
Did not declare & $9.3 \%$ \\
\hline
\end{tabular}

As shown in Table 3, above indicate that the majority of participants with highest qualifications were those with a B. Tech, B. Degree/ Honours with $28.9 \%$ followed by those with the D. Tech/PhD with $24.1 \%$ participated in the paper.

Table 4. Category of employment and Years of service

\begin{tabular}{llll}
\hline Category of employment & $\mathbf{1 0 0 \%}$ & Years of service & $\mathbf{1 0 0 \%}$ \\
\hline Academic & $27.8 \%$ & $1-10$ & $72.6 \%$ \\
Admin and support & $65.8 \%$ & $11-15$ & $4.6 \%$ \\
Did not indicate & $6.5 \%$ & 16 and above & $22.2 \%$
\end{tabular}

As shown in Table 4 , above indicate that the majority of participants category of employment and years of service were admin and support with $65.8 \%$ and the majority on years of service were 1-10 with $72.6 \%$ participated in the paper. 
Table 5. Involvement, feedback and conditions of services

\begin{tabular}{|c|c|c|c|c|c|c|}
\hline Question & $\begin{array}{l}\text { Strongly } \\
\text { disagree }\end{array}$ & Disagree & Natural & Agree & $\begin{array}{l}\text { Strongly } \\
\text { agree }\end{array}$ & Total \\
\hline 5.1 The university involves staff in decision making. & 35.6 & 26.9 & $26.9 \%$ & $5.8 \%$ & $4.8 \%$ & $100 \%$ \\
\hline $\begin{array}{l}5.2 \text { The university has a system/process in place that } \\
\text { encourages employees to offer feedback and ideas. }\end{array}$ & $35.2 \%$ & $32.4 \%$ & $21.9 \%$ & $9.5 \%$ & $1 \%$ & $100 \%$ \\
\hline $\begin{array}{l}5.3 \text { I am satisfied with the conditions of service in the } \\
\text { university. }\end{array}$ & $28.4 \%$ & $29.4 \%$ & $17.6 \%$ & $19.6 \%$ & $4.9 \%$ & $100 \%$ \\
\hline
\end{tabular}

As shown in Table 5, above indicate that if the university involves staff in decision making and the majority strongly disagree were $35.6 \%$. While those indicate that the university has a system/process in place that encourages employees to offer feedback and ideas strongly disagree were $35.2 \%$. The table further reveals that those that are satisfied with the conditions of service in the university were $28.4 \%$.

Table 6. Payments, benefits and promotions processes

\begin{tabular}{|c|c|c|c|c|c|c|}
\hline Question & $\begin{array}{l}\text { Strongly } \\
\text { disagree }\end{array}$ & Disagree & Natural & Agree & $\begin{array}{l}\text { Strongly } \\
\text { agree }\end{array}$ & Total \\
\hline 6.1 I am paid fairly for the work that I do. & $44.3 \%$ & $25.5 \%$ & $12.3 \%$ & $17 \%$ & $0.9 \%$ & $100 \%$ \\
\hline $\begin{array}{l}6.2 \text { I feel that benefits provided by the university } \\
\text { meet my needs well }\end{array}$ & $31.7 \%$ & $32.7 \%$ & $14.4 \%$ & $17.3 \%$ & $3.8 \%$ & $100 \%$ \\
\hline $\begin{array}{l}\text { 6.3 Promotions processes are fair for all staff in the } \\
\text { university. }\end{array}$ & $45.1 \%$ & $26.5 \%$ & $19.6 \%$ & $3.9 \%$ & $4.9 \%$ & $100 \%$ \\
\hline
\end{tabular}

As shown in Table 6, above indicate the majority of the participants indicated that there were paid fairly for the work that they do strongly disagree were $44.3 \%$ while those that indicate that they feel that benefits provided by the university meet their needs well strongly disagree were $31.7 \%$. the table further reveals that promotions processes were fair for all staff in the university strongly disagree were $45.1 \%$.

Table 7. Communication, workload and HR policies

\begin{tabular}{|c|c|c|c|c|c|c|}
\hline Question & $\begin{array}{l}\text { Strongly } \\
\text { disagree }\end{array}$ & Disagree & Natural & Agree & $\begin{array}{l}\text { Strongly } \\
\text { agree }\end{array}$ & Total \\
\hline $\begin{array}{l}\text { 7.1 Communication in the university is open and } \\
\text { clear and there is no need for gossip. }\end{array}$ & $34.3 \%$ & $23.8 \%$ & $22.9 \%$ & $16.2 \%$ & $2.9 \%$ & $100 \%$ \\
\hline $\begin{array}{l}7.2 \text { I work with unreasonable deadlines and heavy } \\
\text { workloads. }\end{array}$ & $9.5 \%$ & $30.25 \%$ & $20 \%$ & $22.9 \%$ & $17.1 \%$ & $100 \%$ \\
\hline $\begin{array}{l}\text { 7.3 The university's HR policies are communicated } \\
\text { clearly to all employees. }\end{array}$ & $41.3 \%$ & $27.9 \%$ & $16.3 \%$ & $6.7 \%$ & $7.7 \%$ & $100 \%$ \\
\hline
\end{tabular}

As shown in Table 7, above indicate the majority of the participants indicated that communication in the university is open and clear and there is no need for gossip were 34.3\%. It further reveals the majority of participant indicated that they work with unreasonable deadlines and heavy workloads disagreed followed by $22.9 \%$ who agreed. and conclude with the majority of those that indicate that the university's HR policies are communicated clearly to all employees were $41.3 \%$.

\section{Discussion}

\subsection{Demographics}

The paper reveals that all employees including those with required qualifications also experience the same factors that affect morale. Senior academics and professors were earning less than junior employees (Africa et al., 2011). The paper is in agreement with Africa et al., (2011) there is discrepancy of salaries in the institutions of higher learning in SA, junior employees earn more that professors and senior managers. Khumalo (2019) urge a need to consider equality in the organisations as it affects employees along the run. This requires management to priorities and benchmark with other institutions of higher learning to avoid losing talent and qualified people. 


\subsection{Management Support and Feedback}

According to Omodan, Tsotetsi, and Dube (2020) advises management support by including all employees in the decision-making in the organisation. The findings of the paper in agreement with authors above as support from management is lacking and employees are not involved in decisions that affect them. This can also lead employee to be demotivated as there are not noticed. Further recommend management to recognise the importance of involving everyone in the issues pertaining employees. Khumalo (2019) emphases a need for management to recognise performance as a strategy for motivation. The paper reveals that there are no system/process in place that encourages employees to offer feedback and ideas in the university they work under. This also contribute to low employee morale. It therefore recommended that all institutions of higher learning to consider the participatory decision making for all to boost the morale of employees now and in future. It is important for the institutions of higher learning to understand that recognising is not the end but using employees' inputs and opinions is required to improve morale.

\subsection{Conditions of Work}

According to NGen (2009) in Erasmus (2020) emphasis that employees get motivated if they work under competent supervision, balance working hours and safe working conditions. Eke and Onuoha (2020) recommended the organisation to improve the conditions of work by training and facilitating employees on opportunities to boost the morale. Working conditions Physical working conditions such as tools, equipment and working space are not provided to some employees. The findings of the paper reveal that employees are not satisfied with the conditions of service of the university their work under. Therefore, the paper recommends that all institution of higher learning should make it a priority that there is a balance of the hours of work and family in general. All institution of higher learning should also ensure that line managers manage work of employees not employees. During covid-19 pandemic most if not all employees working remotely, therefore all necessary tools of work should be provided such as connections and laptops. Those that are working in the office should also be considered with health environment not to share small spaces.

\subsection{Remuneration Packages}

According to Smit and Botha (2016) in Erasmus (2020) once employees realize equal chances of succeeding it improves the level of motivation. One institution of higher learning in SA was rated at 35\% low salaries and unfair labour practices compare to other tertiary institutions. Senior academics and professors were earning less than junior employee (Africa et al., 2011). The findings of the paper support the authors since it reveals that employees are not paid fairly for the work they do. Eke and Onuoha (2020) recommended the organization to work on strong and sustained policies of compensation that can close a gap between unfair payrolls of employees. Further Eke and Onuoha (2020) recommended management to fairly pay their employees for employees who performs same tasks. Therefore, the paper recommends the institutions of higher learning to review and benchmark their salaries across the country and outside. Institutions of higher learning requires their academics to obtain $\mathrm{PhDs}$ and therefore, it is vital that their salaries should be up higher than those that have not PhDs.

\subsection{Benefits}

Compensation and benefit If employees are not fairly compensated, the employees look for other jobs externally (Fathaniy, 2011). The findings of the paper reveal that employees feel that benefits provided by the university does not meet their needs well. Benefits does not improve performance however, influence the satisfaction of employees' commitment (O'Moala laidh, (2000). Further, Eke and Onuoha (2020) recommended organisation to provide benefits also to casual or part-time workers such as health insurance, bonuses and allowances of bus fare. While Nur, Harrison, Deb, Burch \& Straderman (2021) recommended management to offer employees with non-monetary based benefits. It is recommended for the institutions of higher learning to assess their employee turnover in order to verify if it not their benefits that chase talent away. To boost morale in the institutions of higher learning it is vital to consider part-time employees with benefits as they play a crucial role in the performance of the institutions such as bus fare allowances and bonuses for good performance.

\subsection{Promotion Processes and Recognition}

It is the responsibility of an employee to take charge on their development in the careers with the support of training and development from management (Warnich, Carrell, Elbert and Hatfield, 2018). Hiring employees externally rather than developing those in the system internal causes low morale to those who are ignored. Khumalo (2020) recommends the implementation strategies of promotions and growth to enhance quality services. The paper revels that promotion processes were not clear in the institution of higher learning. Fathaniy (2011) said employees need to be 
given opportunities to advance careers in order to grow and develop skills. Promotion policies should be revised in a way that promote quality and contribution of employees (Bourini, 2010). While Nur et al., (2021) recommended management to notify employees about the processes of rewards and promotion. The paper recommends that it is crucial for managements of the institutions of higher learning to train employees about promotion processes for understanding and encouragement. If those who are in the system are ignored and a focus paid more on keeping on recruiting external is another factor that management of the institutions of higher learning should focus on. Institutions of higher learning requires academics to apply for a promotion to senior levels that takes months while there are seen that they do qualify. Promotion policy should be revisited to accommodate those who overqualified to move from junior lectureship to associate professor that to start from moving to lecturer, senior lecturer than associate professor. This also applies to support employees when they have been developed or attain senior qualifications, there should be promoted to the senior vacancy.

\subsection{Communication and Understanding of Policies}

According to Omodan, Tsotetsi, and Dube (2020) communication is the lifeline on the business to their stakeholders as it informs and educates everyone. The paper reveals that the university's HR policies are not communicated clearly to all employees. Odionye (2014) emphasis a need to for the institutions of higher learning to choose the various tools of communication for effective co-operation. The paper recommends the institutions of higher learning to educate employees also in a simple language all the policies and how they influence them. The policies of the institutions of higher learning should accessed by all employees at all levels in different languages. Employees should be engaged formulation of the policies especially that affect them.

\subsection{Treatment and Workload}

Overloaded with work develops confusion and employees fails to meet the targets required (Redfern, Hannan, Norman and Martin (2002). The paper reveals that the employees they work under unreasonable deadlines and heavy workloads. Nur et al., (2021) recommended management to introduce a job rotation system. While Erasmus (2020) recommended the institution of higher learning to assess factors of stress which includes overload and ambiguity on employees. The paper reveals that employees are performing tasks of two or more people donate to confusion, stress, burnout and failing to balance work and life. Workload of academics should be planned accordingly and balanced teaching and learning, research, administration and community engagement. Academics with too much teaching workload result in a shift on other areas of their KPAs which negatively influence the performance and decrease morale that led by demotivation of growth. Management should also consider to add more staff on support since everyone blames them for slow system without understanding the capacity of work. Therefore, the paper recommends the institutions of higher learning to recruit more staff to avoid being the reason of no progression and low morale to their employees.

\section{Conclusion}

The paper assessed the factors that contribute to academics and support employees in the institution of higher learning in SA and reveals that number of factors that need to be addressed as a matter of urgency to avoid losing talent employees. Employees at all levels have significant experiencing similar factors which embedded to low morale. Institutions of higher learning should not ignore these factors as they have huge the consequences. Management support and feedback, conditions of work, remuneration packages, benefits, promotion processes and recognition, communication and understanding of policies as well as treatment and workload were the crucial factors affect the morale of employees. This paper provides a wake-up call to management and leaders to assess their organisations based on these factors and implement interventions that can bring a desired result for future. Management and leaders are the heads of the institutions and employees including both academics and support are the necks of the same heads. Without a neck the head cannot be able to move from one side to another and the whole body will collapse.

\section{Recommendations}

- All institutions of higher learning to review they own policies and ensure that all stakeholders of their institutions understand them effectively.

- The participatory of all stakeholder it vital to implement to ensure recognition and being part of the institution.

- The balance of work and life should also be taking into consideration when allocating duties to employees to refrain from burnout which leads to low morale. 
- Invest on occupying employees with all trade of work either working from home or in the office. Bench marking of salaries is one of the strategies to ensure that institutions not loose talent and qualified employees.

- Training and development to educate people about the necessity requirements to for career growth and advancement.

- A balance of the allocations of duties to employees fairly based on their KPAs to meet the institutional goals and improve performance.

\section{Acknowledgement}

The authors declare that this is original work and never been submitted to other journals for publication. There is no financial or any other relationship that may have inappropriately influenced in writing this article and also like to acknowledge all the participants for willing to participate in this research. The author declares no much competing interest.

\section{Reference}

Adams, A., \& Bond, S. (2007). Hospital nurse's job satisfaction, individual and organisational characteristics. Journal of Advance Nursing, 32(3), 536-543. https://doi.org/10.1046/j.1365-2648.2000.01513.x

Africa, H., Mosia, T., \& Zakuza, T. (2011). Report of the independent assessors in the affairs of the University of Zululand, Notice 172 of 2011No. 34156. Pretoria: Government Printers.

Boomer, L. G. (2008). Trust the confidence to change: Accounting today. Retrieved from: http://www.highbeam.com/doc/1G1-182204678.html.pdf

Bound, H., Evans, K., Sadik, S., \& Karmel. (2018). How non-permanent workers learn and develop challenges and opportunities. (1 ${ }^{\text {st }}$ Edition). Routledge. https://doi.org/10.4324/9781315102993-1

Bourini, I. F. (2010). Relationship between human resource information system and strategic capability among employees in Jordanian Companies. Graduate School of Management, University Utara: Malaysia.

Bowles, D., \& Copper, C. (2009). Employee Morale: Driving performance in changing times. New York: Palgrave Macmillan. Management, New York: Palgrave Macmillan. https://doi.org/10.1057/9780230250789

Drew, S. (2011). Five causes of low employee morale and how to avoid them. Retrieved from: http://www.humanresourcesiq.com/talent-management/articles/5-causes-of-low-employee-morale-and-how-to-a void-t/pdf.

Eke, O., \& Onuoha, B. C. (2020). Casualization \& employee morale in the Oil Industry: A case study of Shell Companies in Nigeria. International Journal of Advance Research, 6(11), 17-31. https://doi.org/10.46654/ij.24889849.s61118

Erasmus, B. (2020). Perceptions of administrative staff on career advancement realities at a South African university. Management, 25(1), 69-88. https://doi.org/10.30924/mjcmi.25.1.4

Farjana Nur, Dean Harrison, Shuchisnigdha Deb, Reuben F. Burch V \& Lesley Strawderman. (2021). Identification of interventions to improve employee morale in physically demanding, repetitive motion work tasks: A pilot case study. Cogent Engineering, 8(1). https://doi.org/10.1080/23311916.2021.1914287

Fathaniy, A. Z. (2011). The role of HR practise, supervisory support and work-life balance policies on employee intention to stay: A study in Oil and Gas Company. Graduate School of Business: University Malaysia.

Haddock, P. (2010). Importance of morale. Retrieved August 15, 2012 from: http://www.ehow.com. Hampshire. Cengage Learning EMEA.

Hayes, S. W., Priestley, Namazbai Iishmakhametov, J. L., \& Ray, H. E. (2020). Kennesaw State University I'm not Working from Home, I'm Living at Work": Perceived Stress and Work-Related Burnout before and during COVID-19. https://doi.org/10.31234/osf.io/vnkwa

Khumalo, N. (2018). The role of human resource planning in producing well-resourced employees to public. Problems and perspectives Management, 16(4), 117-125. https://doi.org/10.21511/ppm.16(4).2018.11

Khumalo, N. (2019). Obstacles of human resource planning that affect workers I delivering services. Problems and perspectives Management, 17(2), 114-123. https://doi.org/10.21511/ppm.17(2).2019.08 
Khumalo, N. (2020). Human resources planning strategies implemented by the service institutions in improving employees' competences. Gender and Behaviour, 18(3).

Kinjerski, V., \& Skrypnek, B. J. (2006). Creating organisational conditions that foster employee spirit at work. Leadership and Organisation Development Journal, 27(4), 280-295. https://doi.org/10.1108/01437730610666037

Lemerle, K. A. (2005). Evaluation the impact of the school environment on teachers' health and job commitment: Is the health promoting school a healthier workplace? School of Public Health: Queensland University of Technology: Australia.

Makawatsakul, B., \& Kleiner, B. H. (2003). The effect of downsizing on morale and attrition. Management Research News, 26(2), 52-62. https://doi.org/10.1108/01409170310783998

Mheidly, N. Fares, M. Y., \& Fares, J. (2020). Coping with stress and Burnout associated with telecommunication and online learning. Public Health. https://doi.org/10.3389/fpubh.2020.574969

Nayak and Singh. (2021). Fundamental of research methodology. Problems and Prospects. SSDN Publishers and Distributors New Delhi.

Ngambi, H. C. (2011). Relationship between leadership and employee morale in Higher Education. African Journal of Business Management, 5(3), 762-776.

N-GEN. (2009). Generational Index. Report on Career Expectations.

O'Maolalaidh, E. (2000). Obtaining Morale in an Irish Retail Company through a combination of open communications, appropriate leadership style, job design and an effective rewards system. National College of Ireland: Dublin.

Ogbe, O. R., Olubummi, O. C., \& Okorobe, E. M. (2019). Effect of casualization on workers performance in organisations. International Journal of Innovation Education and Research, 7(7), 28-38. https://doi.org/10.31686/ijier.vol7.iss7.1554

Omodan, B. I., Tsotetsi, C. T., \& Dube, B. (2020). Analysis of human relations theory of management: A quest to re-enact people's management towards peace in university system. SA Journal of Human Resource Management/SA Tydskrif vir $\quad$ Menslikehulpbronbestuur, $\quad 18(0), \quad$ a1184. https://doi.org/10.4102/sajhrm.v18i0.1184

Redfern, S., Hannan, S., Norman, I., \& Martin, F. (2002). Work satisfaction, stress, and quality of care and morale of older people in a nursing home. Journal of Health and Social Care in the Community, 10(6), 512-517. https://doi.org/10.1046/j.1365-2524.2002.00396.x

Warnich, S., Carrell, M. R., Elbert, N. F., \& Hatfield, R. D. (2018). Human resource management in South Africa.

Webb, D. O. (2014). The relationship between principal leadership and teacher morale in the elementary schools in a northwest Georgia school district. ProQuest LLC.

Zweni, T. (2004). An assessment of the impact of the organisational restructuring on the morale of employees at a selected final institution. Nelson Mandela Metropolitan University: South Africa.

\section{Copyrights}

Copyright for this article is retained by the author(s), with first publication rights granted to the journal.

This is an open-access article distributed under the terms and conditions of the Creative Commons Attribution license (http://creativecommons.org/licenses/by/4.0/). 